\title{
Enhancing Self-efficacy in Vocabulary Learning: A Self-regulated Learning Approach
}

\author{
Atsushi Mizumoto \\ Kansai University \\ doi: http://dx.doi.org/10.7820/vli.v02.1.mizumoto
}

\begin{abstract}
The current study aimed to explore the effects of integrating a selfregulated learning approach on self-efficacy in vocabulary learning. A group of 115 English as a Foreign Language (EFL) learners from a university in Japan participated in this longitudinal study. The participants were assigned as the treatment group, the contrast group 1, and the contrast group 2. Only the treatment group received the intervention based on the self-regulated learning approach. The participants completed a questionnaire on self-efficacy in vocabulary learning three times and a vocabulary test twice. Multilevel analysis of change was employed to examine the trajectories of change in the participants' self-efficacy over the measurement occasions. The gain scores in the vocabulary test were submitted to analysis of variance. The results showed that the treatment group showed a steady increase in self-efficacy and vocabulary knowledge compared with the other two contrast groups. The findings from the current study provide empirical evidence suggesting that through a selfregulated learning approach, it might be possible to enhance self-efficacy, which in turn may contribute to the development of vocabulary knowledge.
\end{abstract}

\section{Background}

It is a well-known fact in vocabulary research and instruction that teachers cannot teach all the words learners may need to know. In fact, Nation (2008) argues that in a well-designed vocabulary development program, the teacher's jobs "in order of importance are planning, strategy training, testing and teaching vocabulary" (p. 1). Teaching comes at the end of the list because vocabulary teaching tends to be inefficient considering that (a) there are simply too many words to deal with, (b) the rate of teaching words has to be slow, (c) the amount of learning is low, and (d) using word cards, or flash-card programs, can result in close to 100\% learning (Nation, 2012).

As learners have to learn vocabulary independently and outside the classroom in most instances, vocabulary learning strategies are of particular importance. This is also why Nation (2008) regards strategy training to be the second most important job in vocabulary teaching. The purpose of strategy training is to get the learners to become independent and autonomous in their vocabulary learning (Nation, 2008, p. 4). A number of studies on voca7bulary learning strategies instruction have been conducted with this goal in mind (e.g., Mizumoto \& Takeuchi, 2009; Rasekh \& Ranjbary, 2003; Zaki \& Ellis, 1999). They have generally reported positive results for strategy instruction, and thus practitioners are now in a better position to incorporate strategy training in their vocabulary teaching. 
In recent years, the concept of language-learning strategies has expanded into a more extensive notion of self-regulated learning, partly in response to a wave of criticism directed at the paucity of rigid theoretical underpinnings (see Cohen \& Macaro, 2007; Dörnyei, 2005; Tseng, Dörnyei, \& Schmitt, 2006 for details). Selfregulated learning, or self-regulation, has been researched mainly within the field of educational psychology. Although several theories of self-regulation exist, Zimmerman's social-cognitive model of self-regulation (1989) suggests that "self-regulation involves learners who proactively direct their behavior or strategies to achieve self-set goals. They also rely on affective, cognitive, motivational, and behavioral feedback to modify or adjust their strategies and behaviors when unable to initially attain their goals" (Cleary \& Zimmerman, 2004, p. 538).

Zimmerman's (1989) cyclical model of self-regulated learning considers selfregulated learning as a process. It consists of three phases: forethought, performance, and self-reflection. In Zimmerman's cyclical model of self-regulated learning, self-efficacy emerges as a key concept. Self-efficacy refers to "the belief in one's capabilities to organize and execute the courses of action required to manage prospective situations" (Bandura, 1995, p. 330).

In theory, engaging in the cyclical model of self-regulated learning will enhance self-efficacy as "(s)elf-regulation affects motivation, emotions, selection of strategies, and effort regulation and leads to increases in self-efficacy and improved academic achievement" (Bembenutty, 2011, p. 4). However, no study to date has investigated the effects of self-regulated learning on self-efficacy in vocabulary learning. In the current study, therefore, the effects of integrating a self-regulated learning approach into regular English courses were examined. The research question of the current study was as follows: will self-efficacy for vocabulary learning be enhanced by integrating a self-regulated learning approach?

\section{Method}

\subsection{Participants}

The study was conducted during the two semesters in the academic year 2012 . The participants were three intact classes of Japanese university English as a Foreign Language (EFL) learners at a private university in western Japan (humanities or engineering majors; aged 18-20). They were first-year students enrolled in a compulsory English course at their university.

The three groups were assigned as (a) the treatment group, (b) the contrast group 1, and (c) the contrast group 2. The participants in the contrast group 1 were of a lower level of English proficiency, and those in the contrast group 2 had the highest level of English proficiency of the three groups. After the list-wise deletion of incomplete cases at the end of the course, the total number of participants amounted to 115 (50 women and $65 \mathrm{men}$ ). The number of participants in each group was: 39 for the treatment group (15 women and 24 men), 40 for the contrast group 1 (15 women and 25 men), and (c) 36 for the contrast group 2 (20 women and 16 men). 


\subsection{Measures}

In order to measure the participants' self-efficacy in vocabulary learning, a questionnaire, comprised of four items, was administered. The items were the same ones used in Mizumoto (2013), in which the validity and reliability of the scale were established. The participants responded on a six-point scale, from 1 (Not at all true of me) to 6 (Very true of me), according to the degree of perception on their learning process. The same questionnaire was administered three times at (a) Time 1: the beginning of the first semester, (b) Time 2: the end of the first semester, and (c) Time 3: the end of the second semester to investigate the changes in the trajectory of self-efficacy. Table 1 shows the descriptive statistics of self-efficacy at three measurement occasions (see Appendix A for the items).

Table 1. Descriptive Statistics of Self-efficacy in Vocabulary Learning

\begin{tabular}{|c|c|c|c|c|c|c|c|}
\hline \multirow[b]{2}{*}{ Group } & \multirow[b]{2}{*}{$n$} & \multicolumn{2}{|c|}{$\begin{array}{c}\text { Time } 1 \\
(\alpha=0.85)\end{array}$} & \multicolumn{2}{|c|}{$\begin{array}{c}\text { Time 2 } \\
(\alpha=0.85)\end{array}$} & \multicolumn{2}{|c|}{$\begin{array}{c}\text { Time 3 } \\
(\alpha=0.85)\end{array}$} \\
\hline & & Mean & $\mathrm{SD}$ & Mean & $S D$ & Mean & $\mathrm{SD}$ \\
\hline Treatment & 39 & 2.70 & 0.95 & 3.21 & 0.89 & 3.43 & 0.78 \\
\hline Contrast 1 & 40 & 2.92 & 0.60 & 3.11 & 0.62 & 3.11 & 0.70 \\
\hline Contrast 2 & 36 & 3.44 & 0.92 & 3.60 & 1.03 & 3.46 & 0.81 \\
\hline
\end{tabular}

Note. The possible range for scores was from 1 to 6 .

In addition to the questionnaire, a vocabulary test was administered, as a measure of vocabulary knowledge (see Appendix B for the sample items). The test was made up of 60 items from the academic vocabulary section of Vocabulary Levels Test (Schmitt, 2000; Schmitt, Schmitt, \& Clapham, 2001), modified by the author (Mizumoto, 2013). This test was administered as a pretest and a posttest to examine the effects of integrating a self-regulated learning approach into regular English courses (Table 2).

Table 2. Descriptive Statistics of Vocabulary Test

\begin{tabular}{|c|c|c|c|c|c|c|c|}
\hline \multirow[b]{2}{*}{ Group } & \multirow[b]{2}{*}{$n$} & \multicolumn{2}{|c|}{$\begin{array}{c}\text { Pretest } \\
(\alpha=0.91)\end{array}$} & \multicolumn{2}{|c|}{$\begin{array}{l}\text { Posttest } \\
(\alpha=0.91)\end{array}$} & \multicolumn{2}{|c|}{ Gain } \\
\hline & & Mean & $\overline{S D}$ & Mean & $\mathrm{SD}$ & Mean & SD \\
\hline Treatment & 39 & 41.67 & 8.36 & 45.41 & 7.65 & 3.74 & 3.80 \\
\hline Contrast 1 & 40 & 38.23 & 9.81 & 39.28 & 9.83 & 1.05 & 3.04 \\
\hline Contrast 2 & 36 & 45.75 & 9.52 & 47.25 & 9.66 & 1.50 & 3.28 \\
\hline
\end{tabular}

Note. The possible range for scores was from 0 to 60 .

\subsection{Procedures}

The three groups of participants met once a week for a 90-minute class during a 15 -week semester. The study lasted two semesters, spanning 30 classes in total (approximately eight months). All three classes used the same textbook, Focus on Vocabulary 1 (Schmitt, Schmitt, \& Mann, 2011). At the beginning of each lesson, 
only the treatment group received a handout, which contained (a) a space to write the learner's specific action plans to achieve their short-term goal by the next lesson (i.e., goal setting), (b) a table describing "what is involved in knowing a word" (Nation, 2001) to draw the learner's attention to a variety of aspects (meaning, form, and use) in learning a word, (c) a space to write the strategies they plan to use to memorize the target vocabulary of the week, (d) a space to write a self-reflection report about their learning, and (e) three self-efficacy rating scales to reflect on their self-regulated learning. The cyclic self-regulative approach (Zimmerman, Bonner, \& Kovach, 1996) was used as a model for instruction.

The session always lasted 10-15 minutes of a 90-minute lesson. For the first few lessons, the teacher, author of this article, described explicitly the key concepts such as self-regulated learning, vocabulary-learning strategies, and metacognitive strategies. The participants were encouraged to exchange their ideas and opinions about the things they wrote down on their handout. This type of interaction was included to help participants understand the different perspectives on vocabulary of other participants.

\subsection{Data analyses}

All the analyses in this study were conducted using $\mathrm{R}$ version 2.14.2. To address the research question of the current study, "Will self-efficacy in vocabulary learning be enhanced by integrating a self-regulated learning approach?" A multilevel analysis of change was employed. Multilevel model, also known by the names such as hierarchical linear model, linear mixed model, mixed-effect model, and random effects model, can be applied to longitudinal data analysis to investigate change over time (specifically called growth curve model in such application). The advantages of these newer statistical models over traditional procedures such as ANOVA can be so great that Second Language Acquisition (SLA) researchers have increasingly started using multilevel modeling (e.g., Kozaki \& Ross, 2011) and mixed-effect modeling (e.g., Ardasheva \& Tretter, 2012; Cunnings, 2012; Sonbul \& Schmitt, 2013), depending on the purpose of the research.

In addition to the longitudinal analysis of self-efficacy in vocabulary learning data, gain scores of vocabulary test (i.e., posttest minus pretest) was submitted to one-way ANOVA with a one between-subject factor (i.e., the type of intervention) to further investigate the effects of integrating a self-regulated learning approach into regular English courses. It should be noted that the result of this analysis is identical with the interaction effect gained in a two-way ANOVA with a one between-subject factor (intervention) and a one within-subject factor (pretest and posttest). Following the one-way ANOVA, post hoc multiple comparison tests were performed using the Tukey procedure.

\section{Results and discussion}

Table 3 is a summary of the results of multilevel analyses of change. Model A is the unconditional means model, and it is the first step to confirm that it is justifiable to employ the multilevel analysis (Singer \& Willett, 2003). Especially, the 
Table 3. Results of Multilevel Analyses of Change

\begin{tabular}{|c|c|c|c|c|c|c|}
\hline & & Parameter & Model A & Model B & Model C & Model D \\
\hline \multicolumn{7}{|l|}{ Fixed effects } \\
\hline \multirow[t]{3}{*}{ Initial status $\left(\pi_{0 \mathrm{i}}\right)$} & Intercept & $\gamma_{00}$ & $3.21^{*}$ & $3.05^{*}$ & $3.15^{*}$ & $3.24^{*}$ \\
\hline & Intervention & $\gamma_{01}$ & & & -0.10 & $-0.19^{*}$ \\
\hline & Pretest & $\gamma_{02}$ & & & & $0.05^{*}$ \\
\hline \multirow{3}{*}{$\begin{array}{l}\text { Rate of change } \\
\left(\pi_{1 i}\right)\end{array}$} & Intercept & $\gamma_{10}$ & & $0.16^{*}$ & 0.03 & 0.01 \\
\hline & Intervention & $\gamma_{11}$ & & & $0.13^{*}$ & $0.15^{*}$ \\
\hline & Pretest & $\gamma_{12}$ & & & & $-0.01^{*}$ \\
\hline \multicolumn{7}{|c|}{ Random effects (variance components) } \\
\hline Level 1 & Within-person & $\sigma_{\varepsilon}^{2}$ & 0.21 & 0.15 & 0.15 & 0.15 \\
\hline \multirow[t]{2}{*}{ Level 2} & Initial status & $\sigma_{0}^{2}$ & 0.54 & 0.69 & 0.68 & 0.42 \\
\hline & $\begin{array}{l}\text { Rate of } \\
\text { change }\end{array}$ & $\sigma_{1}^{2}$ & & 0.03 & 0.02 & 0.01 \\
\hline \multirow[t]{3}{*}{ Goodness-of-fit } & $\mathrm{AIC}$ & & 695.05 & 662.87 & 651.31 & 609.25 \\
\hline & $\mathrm{BIC}$ & & 706.58 & 685.93 & 682.06 & 647.69 \\
\hline & $-2 \log \mathrm{Lik}$ & & 689.05 & 650.87 & 635.31 & 589.25 \\
\hline
\end{tabular}

${ }^{*} p<0.05$.

intraclass correlation coefficient ( $\rho$ ) shows the relative magnitude of total variation, which is derived from the between-person variance component (Level 2). Estimation of $\rho$ can be obtained from the following equation:

$$
\rho=\frac{\sigma_{0}^{2}}{\left(\sigma_{0}^{2}+\sigma_{\varepsilon}^{2}\right)}
$$

For Model A, $\rho$ is 0.72 , indicating large variation in self-efficacy can be explained with differences among individuals. This result warrants subsequent analyses with the multilevel modeling.

Model B is the unconditional growth model with time (i.e., Time 1, 2, and 3) as the only predictor. The result suggests that overall self-efficacy of the participants in the current study steadily increased with the slope of $0.16\left(\gamma_{10}\right)$ from the initial intercept of $3.05\left(\gamma_{00}\right)$. Model $\mathrm{C}$ includes intervention $\left(\gamma_{01}\right.$ and $\left.\gamma_{11}\right)$ as a predictor of initial status and rate of change. Model D adds pretest $\left(\gamma_{02}\right.$ and $\gamma_{12}$ ) to Model $\mathrm{C}$ to control for the effects of pretest on initial status and rate of change. The inclusion of the vocabulary pretest scores in the model was legitimate because self-efficacy and proficiency (i.e., vocabulary knowledge) would be related to each other. In fact, Model D showed the best goodness-of-fit indexes (the smaller the value, the better fit it is) among all the models. To improve the interpretability of the parameters, pretest scores were recentered on the sample means (Singer \& Willett, 2003, p. 113). The parameters $\gamma_{11}$ and $\gamma_{11}$ in Model D indicate that selfefficacy among the three groups differs after controlling for the effects of pretest.

The final model (Model D) of the current study can be expressed as follows:

Level 1 (within-person) $Y_{i j}=\pi_{0 i}+\pi_{1 i} T I M E_{i j}+\varepsilon_{i j}$

Level 2 (between-person) $\pi_{0 i}=\gamma_{00}+\gamma_{01}$ INTERVENTION $+\gamma_{02}$ PRETEST $+\zeta_{0 i}$

$$
\pi_{1 i}=\gamma_{10}+\gamma_{11} \text { INTERVENTION }+\gamma_{12} \text { PRETEST }+\zeta_{1 i}
$$


where $i$ represents the learner and $j$ the measurement occasion. By using this equation and the fixed effects in Model $\mathrm{D}\left(\gamma_{00}, \gamma_{01}, \gamma_{02}, \gamma_{10}, \gamma_{11}\right.$, and $\left.\gamma_{12}\right)$, the predicted self-efficacy for each group can be obtained (displayed in Figure 1, bottom panel). As is evident from Figure 1, the treatment group showed a steady

Plotting Raw Scores

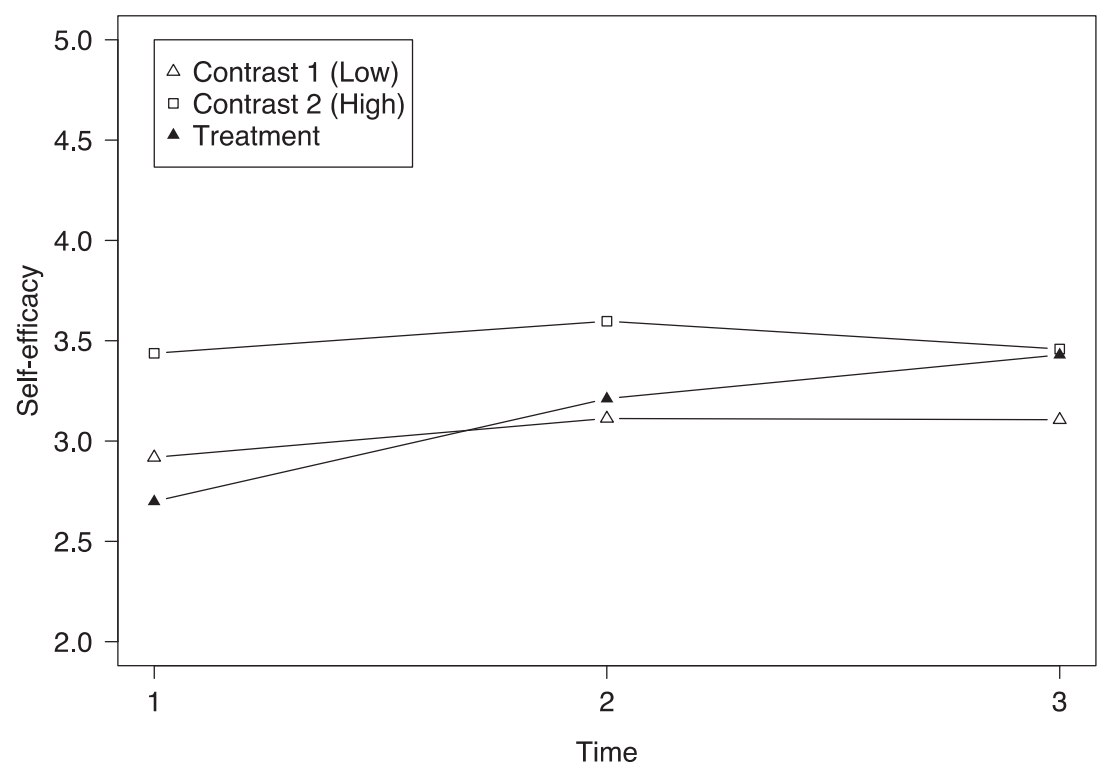

Fitting Model D

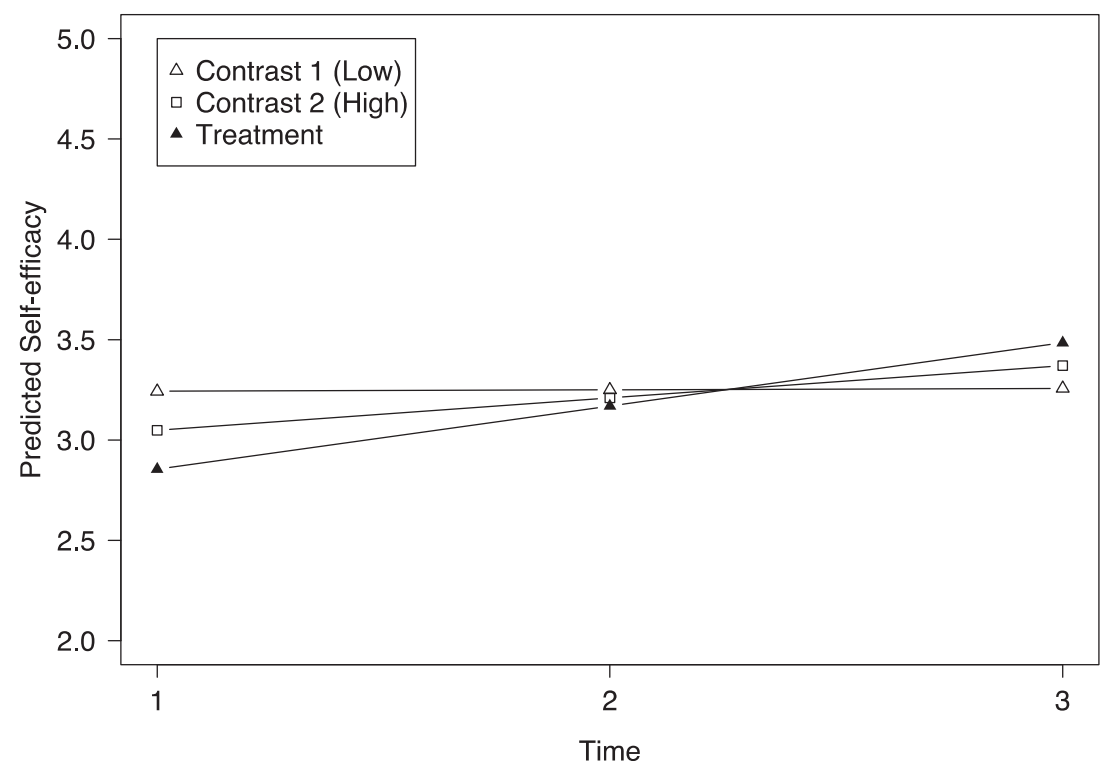

Figure 1. Plotting raw scores (top panel) and displaying the results of the fitted multilevel models for change (bottom panel). 
increase in self-efficacy during the three measurement occasions. Both the contrast groups stayed almost the same during the period. This result, along with the result of the multilevel modeling, suggests that self-efficacy in vocabulary learning can be enhanced by integrating a self-regulated learning approach.

Table 4 presents a summary of the results of a one-way ANOVA of the gain scores of vocabulary test, and Table 5 the results of post hoc multiple comparison tests with the Tukey procedure. One-way ANOVAs confirmed that statistically significant differences were found in the gain scores of the vocabulary test for the three groups compared. The results of post hoc multiple comparison tests showed that statistically significant differences existed between the treatment group and the other two contrast groups. The result indicates that the treatment group exhibited a greater gain in their vocabulary knowledge than the other two contrast groups. These trajectories of change in vocabulary knowledge are in line with the patterns observed in self-efficacy (i.e., the treatment group showed a steady increase compared with the other two contrast groups).

Table 4. Results of One-way ANOVA (Gain Scores in Vocabulary Test)

\begin{tabular}{lrrcccc}
\hline Source & \multicolumn{1}{c}{ df } & \multicolumn{1}{c}{ SS } & MS & $F$ & $p$ & $\eta^{2}$ \\
\hline Intervention & 2 & 162.41 & 81.21 & 7.07 & 0.001 & 0.11 \\
Residuals & 112 & 1286.34 & 11.49 & & & \\
\hline
\end{tabular}

Table 5. Results of Multiple Comparisons (Gain Scores in Vocabulary Test)

\begin{tabular}{lcrccc}
\hline & & \multicolumn{2}{c}{$95 \% \mathrm{Cl}$} & & \\
\cline { 3 - 4 } Comparisons & Difference & Lower & Upper & $p$ & $d$ \\
\hline Contrast 1 - Contrast 2 & 0.45 & -1.40 & 2.30 & 0.832 & 0.14 \\
Contrast 1 - Treatment & 2.69 & 0.88 & 4.51 & 0.002 & 0.78 \\
Contrast 2 - Treatment & 2.24 & 0.38 & 4.10 & 0.014 & 0.63 \\
\hline
\end{tabular}

Note. Refer to Table 2 for the gain score means and standard deviations.

Taken together, these results provide empirical evidence to answer the research question of the current study: "Will self-efficacy in vocabulary learning be enhanced by integrating a self-regulated learning approach?" That is, integrating a self-regulated learning approach in a regular class sessions will enhance selfefficacy in vocabulary learning. Furthermore, from the results of the gain score analyses in the vocabulary test, it would be reasonable to assume that the enhanced self-efficacy through a self-regulated learning approach may lead to a gain in vocabulary knowledge.

\section{Conclusion}

The current study is aimed at exploring the effects of integrating a selfregulated learning approach on self-efficacy with vocabulary learning. The findings 
from the current longitudinal study suggest that through a self-regulated learning approach, it would be possible, for teachers and learners alike, to enhance selfefficacy, which in turn may contribute to the development of vocabulary knowledge.

The pedagogical implication of results of the current study relates to the importance of measuring self-efficacy as a measure of mastery in vocabulary learning. Thus, self-efficacy should be measured and teachers are encouraged to enhance it through the instruction of self-regulated learning or vocabulary learning strategies as part of the language-focused learning strand (Nation, 2007). With the enhancement of self-efficacy at its core, teachers can provide instructions for vocabulary learning strategies, or more encompassing concept self-regulated learning, to help the learners become more autonomous.

\section{Acknowledgments}

This research was made possible by a Grant-in-aid for Scientific Research (No. 24720276) from the Japan Society for the Promotion of Science. I would like to thank the anonymous reviewers of Vocabulary Learning \& Instruction for their insightful comments and suggestions on the manuscript.

\section{References}

Ardasheva, Y., \& Tretter, T.R. (2012). Contributions of individual differences and contextual variables to reading achievement of English language learners: An empirical investigation using hierarchical linear modeling. TESOL Quarterly. Advance online publication. doi:10.1002/tesq. 72

Bandura, A. (1995). Self-efficacy in changing societies. New York: Cambridge University Press. doi:10.1017/CBO9780511527692

Bembenutty, H. (2011). Introduction: Self-regulation of learning in postsecondary education. In H. Bembenutty (Ed.), Self-regulated learning (pp. 2-8). San Francisco, CA: Jossey-Bass, a Wiley Imprint.

Cleary, T.J., \& Zimmerman, B.J. (2004). Self-regulation empowerment program: A school-based program to enhance self-regulated and self-motivated cycles of student learning. Psychology in the Schools, 41, 537-550. doi:10.1002/pits. 10177

Cohen, A.D., \& Macaro, E. (Eds.). (2007). Language learner strategies: Thirty years of research and practice. Oxford: Oxford University Press.

Cunnings, I. (2012). An overview of mixed-effects statistical models for second language researchers. Second Language Research, 28, 369-382. doi:10.1177/ 0267658312443651

Dörnyei, Z. (2005). The psychology of the language learner: Individual differences in second language acquisition. Mahwah, NJ: Lawrence Erlbaum Associates.

Kozaki, Y., \& Ross, S.J. (2011). Contextual dynamics in foreign language learning motivation. Language Learning, 61, 1328-1354. doi:10.1111/j.1467-9922. 2011.00638.x 
Mizumoto, A. (2013). Effects of self-regulated vocabulary learning process on selfefficacy. Manuscript submitted for publication.

Mizumoto, A., \& Takeuchi, O. (2009). Examining the effectiveness of explicit instruction of vocabulary learning strategies with Japanese EFL university students. Language Teaching Research, 13, 425-449. doi:10.1177/136216880 9341511

Nation, I.S.P. (2001). Learning vocabulary in another language. Cambridge: Cambridge University Press. doi:10.1017/CBO9781139524759

Nation, I.S.P. (2007). The four strands. Innovation in Language Learning and Teaching, 1, 2-13. doi:10.2167/illt039.0

Nation, I.S.P. (2008). Teaching vocabulary: Strategies and techniques. Boston, MA: Heinle, Cengage Learning.

Nation, I.S.P. (2012). Is it worth teaching vocabulary? Plenary presentation at the Independent Learning Association Conference (ILAC) 2012, Wellington, NZ.

Rasekh, Z.E., \& Ranjbary, R. (2003). Metacognitive strategy training for vocabulary learning. Teaching English as a Second or Foreign Language Electronic Journal, 7 (2). Retrieved from http://tesl-ej.org/ej26/a5.html

Schmitt, N. (2000). Vocabulary in language teaching. Cambridge: Cambridge University Press.

Schmitt, N., Schmitt, D., \& Clapham, C. (2001). Developing and exploring the behaviour of two new versions of the Vocabulary Levels Test. Language Testing, 18, 55-88. doi:10.1177/026553220101800103

Schmitt, D., Schmitt, N., \& Mann, D. (2011). Focusing on vocabulary 1: Bridging vocabulary. New York, NY: Longman Education.

Singer, J.D., \& Willett, J.B. (2003). Applied longitudinal data analysis: Modeling change and event occurrence. New York, NY: Oxford University Press. doi:10. 1093/acprof:oso/9780195152968.001.0001

Sonbul, S., \& Schmitt, N. (2013). Explicit and implicit lexical knowledge: Acquisition of collocations under different input conditions. Language Learning, 63, 121-159. doi:10.1111/j.1467-9922.2012.00730.x

Tseng, W.-T., Dörnyei, Z., \& Schmitt, N. (2006). A new approach to assessing strategic learning: The case of self-regulation in vocabulary acquisition. Applied Linguistics, 27, 78-102. doi:10.1093/applin/ami046

Zaki, H., \& Ellis, R. (1999). Learning vocabulary through interacting with a written text. In R. Ellis (Ed.), Learning a second language through interaction (pp. 153-169). Amsterdam: John Benjamins.

Zimmerman, B.J. (1989). A social cognitive view of self-regulated academic learning. Journal of Educational Psychology, 81, 329-339. doi:10.1037/00220663.81.3.329

Zimmerman, B.J., Bonner, S., \& Kovach, R. (1996). Developing self-regulated learners: Beyond achievement to self-efficacy. Washington, DC: American Psychological Association. doi:10.1037/10213-000 


\section{Appendix A: The Questionnaire Items Measuring Self-efficacy in Vocabulary Learning}

1. I am good at memorizing vocabulary.

2. I know more vocabulary than others.

3. I know basic vocabulary to some extent.

4. I believe that I can get a good score in the vocabulary test.

\section{Appendix B: Sample Items of the Vocabulary Test Used in the Study}

Choose the best answer for the definition.

1. Work
(A) Benefit (B) Function
(C) Labor (D)
(D) Structure

2. Part of 100
(A) Percent
B) Period (C)
(C) Policy
(D) Process

3. General idea used to guide one's actions

(A) Principle (B) Region (C) Source (D) Survey

4. Money for a special purpose

(A) Circumstance (B) Corporation (C) Fund (D) Layer

5. Skilled way of doing something

(A) Document (B) Immigrant (C) Shift (D) Technique 